\title{
COVID-19: Targeting Proteases in Viral Invasion and Host Immune Response
}

\author{
Sanchit Seth, Jyotsna Batra and Srilakshmi Srinivasan* \\ School of Biomedical Sciences, Faculty of Health, Translational Research Institute, Queensland University of Technology, \\ Brisbane, QLD, Australia
}

An acute respiratory disorder (COVID-19) that accelerated across the globe has been found to be caused by a novel strain of coronaviruses (SARS-CoV-2). The absence of a specific antiviral drug or vaccination has promoted the development of immediate therapeutic responses against SARS-CoV-2. As increased levels of plasma chemokines and, cytokines and an uncontrolled influx of inflammatory cells were observed in lethal cases, it was concluded that the severity of the infection corresponded with the imbalanced host immunity against the virus. Tracing back the knowledge acquired from SERS and MERS infections, clinical evidence suggested similar host immune reactions and host ACE2 receptor-derived invasion by SARS-CoV-2. Further studies revealed the integral role of proteases (TMPRSS2, cathepsins, plasmin, etc.) in viral entry and the immune system. This review aims to provide a brief review on the latest research progress in identifying the potential role of proteases in SARS-CoV-2 viral spread and infection and combines it with already known information on the role of different proteases in providing an immune response. It further proposes a multidisciplinary clinical approach to target proteases specifically, through a combinatorial administration of protease inhibitors. This predictive review may help in providing a perspective to gain deeper insights of the proteolytic web involved in SARS-CoV-2 viral invasion and host immune response.

Keywords: SARS-CoV-2, proteases, immune response, invasion, COVID-19

\section{INTRODUCTION}

Since early 2020, the world has been experiencing the uncontrollable spread of novel coronavirus (2019-nCOV) dependent acute respiratory illness, the outbreak of which was first reported in the city of Wuhan, Hubei, China in late 2019. As of May 11, 2020, there have been more than four million confirmed cases globally with over 280,000 deaths till date. The common clinical symptoms in patients include fever, cough, and fatigue, with gastrointestinal infection for a small group of the population (Wu F. et al., 2020). Next generation sequencing (NGS) revealed a genome sequence similarity between, and distinct genomic composition of, the causative agent of SARS$\mathrm{CoV}$ and MERS-CoV, identified in 2002/03 and 2011 respectively, that caused global pandemics of Severe Acute Respiratory Syndrome (SARS) and Middle East Respiratory Syndrome (MERS) (Wu F. et al., 2020). Full-length genome sequences obtained from five patients suffering from an early stage of illness revealed a $79.6 \%$ sequence identity to SARS-CoV and $96 \%$ identicality at the whole-genome level to a bat coronavirus (Zhou et al., 2020). Hence, on February 11, 2020 
the World Health Organisation (WHO) officially named the disease as coronavirus disease 19 (COVID-19) and the new corona virus as SARS-CoV-2. Virus infectivity tests showed angiotensin converting enzyme II (ACE2) receptor as the cellular entry receptor, which is the previously known cell receptor for SARS-CoV (Wu F. et al., 2020) for human infections. The genomic and clinical symptomatic identicality observed between SARS-CoV and SARS-CoV-2 allowed researchers to predict the host immune response and explore how SARS-CoV-2 may evade the host response. This review focuses on gathering recent clinical data on the host immune response and correlating these with our current knowledge about the viruses, providing updates on the application of host cell proteases as a potential therapeutic approach against COVID-19 viral replication, and discussing the severity of disease.

\section{SARS-CoV-2: GENOMIC STRUCTURE AND PATHOGENESIS}

Isolation of one strain of SARS-CoV-2 from a COVID-19 pneumonia patient from Wuhan seafood market revealed to be $29.9 \mathrm{~kb}$ (Wu F. et al., 2020) non-segmented positivesense RNA $\beta$-coronavirus (Zhu et al., 2020). When compared to the RNA genome of SARS-CoV and MERS-CoV, 27.9 and $30.1 \mathrm{~kb}$, respectively (de Wit et al., 2016), SARS-CoV-2 contains 6-11 open reading frames (ORFs). Two polyproteins, ppla and pplab, and 16 non-structural proteins (NSP) are encoded by the first ORF (ORF $1 \mathrm{a} / \mathrm{b}$ ) which covers twothirds of the viral RNA. The remaining viral genomes encode several accessory proteins and four essential structural proteins, including small envelope (E) protein, nucleocapsid (N) protein, spike (S) glycoprotein, and matrix (M) protein (Cui et al., 2019), involved in potential interference with the host innate immune response. Meta-transcriptomic sequencing on the same sample showed the genomic and phylogenetic similarity of SARS-CoV-2 to SARS-CoVs, particularly in the S-protein and receptor binding domain (RBD), revealing the capability of human transmission of COVID-19 (Wu A. et al., 2020). The protein level mutation observed in NSP2, NSP3, $\mathrm{RBD}$, and spike protein indicated its role in severity of infection, differentiation mechanism, and spread of the disease (Angeletti et al., 2020).

The cross-species and human-to-human transmission of COVID-19 through the ACE2 cellular entry receptor was confirmed by Zhou et al. (2020). It involves the attachment of virion $S$-glycoprotein to the ACE2 receptor presented by human cells through the $S 1$ sub-unit, leading to the virusmembrane fusion by the S2 sub-unit of the glycoprotein (Zhang et al., 2014). Upon fusion, the viral genomic RNA is released in the cytoplasm, translating the non-structural proteins to form replication-transcription complex (RTC) (Sawicki and Sawicki, 2005). Continuous replication of RTC leads to the synthesis of sub-genomic RNAs, encoding the structural and accessory proteins (Hussain et al., 2005). Newly formed genomic RNA envelope glycoproteins and nucleocapsid proteins and, interact with endoplasmic reticulum and golgi to form viral particle buds that finally fuse with the plasma membrane of the host cell to release the virus (Perrier et al., 2019).

As it is established that SARS-CoV-2 shares the same cellular entry receptor as SARS-CoV, the ACE2 binding efficacy of S-protein was observed to be 10-20 fold higher in SARSCoV-2 in a recent study (Song et al., 2018). It was also observed that human cells expressing ACE2 but not human Dipeptidyl peptidase-4 (DPP4) or Aminopeptidase N (APN) were less susceptible to the human cell entry of SARS-CoV2 (Letko et al., 2020). The priming of Spike (S) protein following the binding to the ACE2 receptor results in the viral- host cell fusion (Tortorici and Veesler, 2019). The cathepsin L-dependent viral glycoprotein activation via SARS$\mathrm{CoV}$ S-protein cleavage at S1/S2 boundary under low $\mathrm{pH}$ conditions and involvement of transmembrane protease serine 2 (TMPRSS2) in triggering the cleavage of trimer S-protein (Simmons et al., 2005; Millet and Whittaker, 2015) opened new avenues to study the role and participation of different proteases in the endocytosis of SARS-CoV-2 into human cells as well as potential for drug targeting and vaccine development. The observed increase in binding efficiency of SARS-CoV-2 S-glycoprotein to the host receptor can be related to the codon mutations observed in the protein sequence, resulting in a plausible increase in the site-specific priming activity of proteases and cathepsins, leading to the highly contagious nature of SARS-CoV-2 as compared to SARS and MERS. Proteases belonging to the proprotein convertase family, including furin and furin-like serine proteases, were analyzed for their ubiquitous role in viral entry and spread. Although produced in the endoplasmic reticulum and role in the viral biosynthesis, these furin and furin-like proteases were found translocated through secretory pathways to access viral S-protein and promote viral entry to host cells (Seidah and Prat, 2012). A recent study presented results supporting the presence of a furin-like cleavage site in the spike protein of SARS-CoV2, which was absent in the other beta coronaviruses (Coutard et al., 2020). It was previously presented that, compared to lower pathogenic forms of the influenza virus, highly pathogenic versions selectively possess a furin-like cleavage site, replaced by a single basic residue cleavage site present in the less pathogenic viruses (Sun et al., 2010; Kido et al., 2012). Another group of researchers correlated the presence of a furin site in the envelope protein to the elevated levels of plasminogen observed in severe COVID-19 patients (Ji et al., 2020). Further research focusing on site-specific binding studies could be an approach to reveal potential druggable targets involving different proteases and specific peptide inhibitors.

\section{SARS-CoV-2: HUMAN IMMUNE RESPONSE AND IMMUNOPATHOLOGY}

The preliminary host innate immune response initiates as soon as the viral particles (RNAs and viral proteins) enter the host cell. Pattern recognition receptors (PRRs), including Toll-like receptors (TLR)-3, TLR-7, TLR-8, and TLR-9 
(Alexopoulou et al., 2001; Wu and Chen, 2014), endosomal RNA receptor, and the cytosolic RNA sensor (RIG-I/MDA5), recognizes the pathogen-associated molecular patterns (PAMPs) (viral proteins and nucleic acids), induces complex signaling to activate transcription factor nuclear factor- $\mathrm{KB}(\mathrm{NF \kappa \textrm {B }})$ and interferon regulatory factor-3 (IRF-3), which leads to the production of type I Interferons (IFN- $\alpha / \beta$ ) (Kawai and Akira, 2010) and the recruitment of a series of pro-inflammatory cytokines, acting as the first line of defense against virus invasion. The production of IFN- $\alpha / \beta$ further initiates the transcription of IFN-stimulated genes (ISGs) via the activation of the JAK-STAT pathway and formation of a complex with IRF9 (de Wit et al., 2016). Hence, a successful initiation of IFN- $\alpha / \beta$ response should lead to the suppression of viral replication at an early stage. While immune response plays a crucial role in combating an infection, it may also result in immunopathogenesis. Research derived from SARS infection cases correlated acute respiratory distress syndrome (ARDS) to the early activation of IFN- $\gamma$ and IFN $\alpha$ and upregulation of proteins encoded by ISGs, pro-inflammatory cytokines, and chemokines, particularly IL-6, -8, CXC-chemokine ligand 10 (CXCL10), and CC-chemokine ligand 2 (CCL2) (Tang et al., 2005; Baas et al., 2006). Furthermore, in comparison to the survivors of SARS-CoV infections, low levels or an absence of spike-specific antibodies were observed in patients who succumbed to disease, suggesting the relatability of disease severity to the lack of an innate adaptive immune response switch (Cameron et al., 2007).

Depending on the duration and severity of the disease, varied host innate immune responses were observed from the limited information available on patients suffering from COVID-19. In one of the reports from Wuhan, increased levels of serum IL-6, neutrophils, and C-reactive protein with reduced total lymphocytes were observed in a study on 99 patients (Zhou et al., 2020). Another independent study of 41 patients presented similar results for patients admitted to the Intensive Care Unit (ICU) vs. non-ICU patients, correlating the increase of neutrophils and reduction of lymphocytes to disease severity and death (Wu F. et al., 2020). Furthermore, in COVID-19 patients, elevated levels of plasma chemokines and cytokines, including granulocyte colony-stimulating factor (G-CSF), macrophage colonystimulating factor (MCSF), hepatocyte growth factor (HGF), IP-10, MCP-1, IFN- $\gamma$, TNF- $\alpha$, MIP- $1 \alpha$ and IL $-1,-2,-4,-7$, $-10,-12,-13$, and -17 , were observed (Chen et al., 2020; Wang et al., 2020). These clinical observations directed toward the involvement of highly pro-inflammatory conditions, like what was seen during SARS-CoV and MERS-CoV infections, further suggest a similar cytokine stormmediated severity of the disease. An anatomy report of a deceased patient suffering from COVID-19 showed a severe inflammatory response in the lower airway, causing lung injury (Guo et al., 2020), potentially caused by a "cytokinestorm."

Based on the limited current data and similarity of COVID19 to earlier $\mathrm{CoV}$ infections, it can be predicted that innate immune response plays an important protective or destructive role, depending on the progression of the disease. Sharing the same ancestor as SARS-CoV, there is a possibility that both structural and non-structural viral proteins of SARSCoV-2 might interfere with the activation of type 1 IFN, resulting in the alteration of its production (Shahabi et al., 2020). Hence, active viral replication in the early stage could later result in hyperproduction of type 1 IFN, leading to a great influx of pro-inflammatory cytokines, including neutrophils and macrophages, causing complications like ARDS, arrythmia, shock, and fatal pneumonia (Wang et al., 2020). Being the key link between the innate and active immune response switch (Tang et al., 2008), in-depth research aiming at targeting IFNs could be an optimum approach to control the imbalance in the immune reactions occurring at the later stage of the infection.

\section{SARS-CoV-2: HUMAN PROTEASES INVOLVEMENT IN INVASION AND IMMUNE RESPONSE}

The role of proteases in SARS-CoV-related viral transmissibility and replication has long been under investigation. It has been presented previously that the entry of virus into the host cell was facilitated by the binding of the surface sub-unit, S1, of the S glycoprotein to the cell surface. Furthermore, the involvement of host proteases (Table 1) in priming the S glycoprotein at S1/S2 and S2' sites has been confirmed by various researchers. A recent study revealed S-protein priming activity by host serine protease TMPRSS2, allowing the ACE2 receptor dependent viral and host cell membrane fusion via S2 subunit (Figure 1) (Matsuyama et al., 2010; Glowacka et al., 2011). Milewska et al. (2020) described the role of kallikrein-related peptidase 13 (KLK13) in specific cleaving of the S1/S2 region in Human coronavirus HKU1, directed toward the potential administration of protease inhibitors to inhibit viral entry. Following the similarity between SARS-CoV and SARS-CoV-2's mode of entry by the ACE2 receptor, a recent study by Hoffmann et al. (2020) revealed the partial blockage of S-protein driven entry of SARS-CoV-2 by administering clinically proven serine protease inhibitor camostat mesylate. Further, full inhibition was observed when the camostat mesylate was coupled with Cathepsin B/L inhibitor E-64d, indicating alternate protein priming by endosomal cysteine proteases Cathepsin B/L (Hoffmann et al., 2020). These results were in concert with another study where SPINT2 geneencoded protease inhibitor targeted TMPRSS2 and led to the restriction of cleavage-activation and viral growth for a range of influenza viruses (Straus et al., 2020). Furthermore, the role of KLK1 and KLK5 in influenza viral infection enhancement and its inhibition by Kallistatin was well established by Leu et al. (2015) and Magnen et al. (2017). Knowing the co-localization and involvement of TMPRSS2 in activating other serine proteases like, KLK4 and KLK14 (Reid et al., 2017), the recently presented results offers the potential to understand the proteolytic web cascade aiding SARS-COV2 entry into the host cell, and the combinatorial inhibitor 
TABLE 1 | Summarizing potential host proteases contributing to viral entry and uncontrolled immune response against viral infection.

\begin{tabular}{|c|c|c|c|}
\hline Causative agent & Contributing host protease & Mechanism involved & References \\
\hline \multirow[t]{4}{*}{ SARS-COV } & HAT & Spike protein priming, leading to ACE2 receptor dependent viral entry & Bertram et al., 2011 \\
\hline & TTSPs & & \\
\hline & Factor Xa & & \\
\hline & TMPRSS11a & & \\
\hline \multirow[t]{2}{*}{ SARS-CoV-2 } & TMPRSS2 & & \\
\hline & Cathepsin B/L & & \\
\hline HKU1 & KLK13 & $\begin{array}{l}\text { Involved in assisting human coronavirus entry by specific cleaving at } \\
\text { S1/S2 site }\end{array}$ & Milewska et al., 2020 \\
\hline \multirow[t]{2}{*}{ Influenza Virus } & KLK1 & Involved in cleavage of hemagglutinin, enhancing the viral production & Leu et al., 2015 \\
\hline & KLK5 & & Magnen et al., 2017 \\
\hline \multirow[t]{4}{*}{ Neutrophils } & Cathepsin C & Activation of several pro-inflammatory serine proteases & Méthot et al., 2007 \\
\hline & Proteinase 3 & $\begin{array}{l}\text { Overexpression leads to uncontrolled degradation of extracellular matrix } \\
\text { and inflammatory responses }\end{array}$ & van der Geld et al., 2001 \\
\hline & Cathepsin G & & Mambole et al., 2008 \\
\hline & Neutrophil Elastase & Affects the levels of growth factor $\alpha$ and stimulates mucus secretion. & $\begin{array}{l}\text { Nakamura et al., 1992; } \\
\text { Roghanian and Sallenave, } 2008\end{array}$ \\
\hline Mast Cells & Tryptase, Chymase & $\begin{array}{l}\text { Due to absence of protease inhibitors in lungs, uncontrolled elevated } \\
\text { expression of granzymes lead to degradation of extracellular matrix and } \\
\text { induce the induction of pro-inflammatory cytokines. }\end{array}$ & Pejler et al., 2007 \\
\hline NK cells & Granzymes A, B, H, K and M & & Morice et al., 2007 \\
\hline T cells & & & $\begin{array}{l}\text { Zhu et al., 2009; Jahrsdörfer } \\
\text { et al., } 2010\end{array}$ \\
\hline B cells & & & Hagn et al., 2009 \\
\hline
\end{tabular}

administration approach could be considered beneficial to restrict the viral entry.

Proteases also play a crucial role in presenting an immune response against the infection. Immune cells express a variety of serine proteases like neutrophil elastase, mast cell tryptase, and thrombin (Table 1) (Heutinck et al., 2010). Following the pattern of immune-pathogenic reactions and cytokine storms observed in fatal cases, a vivid correlation between an imbalanced immune response and disease severity led to the prospect of targeting proteases to eventually control the higher threshold of immune response (Figure 2). A recent study has revealed the association between human serine proteases trypsin, thrombin, tryptase, and elastase with increased expression of MCP-1 (Wang et al., 2007). Inhibition of these proteases resulted in the inhibition of MCP-1 secretion via inactivation of various protease-activated receptors (PARs), leading to the abolishment of its chemotactic activity (Wang et al., 2007). Furthermore, neutrophils respond to viral infections by activation of neutrophil elastase, Cathepsin $\mathrm{G}$, and proteinase 3, playing roles both intracellularly and extracellularly (Méthot et al., 2007; Heutinck et al., 2010). However, activity of neutrophil proteases hinders the viral cell cycle and growth intracellularly and the presence of a high number of neutrophils at the inflammation site could correspond to imbalanced protease activity. This further leads to various inflammatory disorders, tissue damage, lung dystrophy, ARDS, and potentially death (Heutinck et al., 2010). Heutinck et al. (2010) showed significant correlation of neutrophil-derived and overexpressed KLK1 with the inflammation of the respiratory tract (Magnen et al., 2017). Relating to the similar clinical diagnosis for COVID-19, it can be deduced that serine proteases play an integral role in both viral invasion and adverse host immune response, further stimulating the pathway for more comprehensive investigations in relation to the specific activity of these proteases and their inhibitors to combat death-causing severity of the disease.

\section{COVID-19 FOCUSED TREATMENTS}

Due to the lack of antiviral therapies against the novel virus and the rapid spread of the outbreak globally, research groups are focusing on treatments using the knowledge previously gathered from SARS and MERS coronaviruses. The current treatments are broadly focused on alleviating symptoms and offering respiratory support using oxygen therapy, ventilators, etc. Antiviral drugs, including ganciclovir, ribavirin, peramivir, and methylprednisolone, previously clinically practiced for influenza virus, failed to show response against SARS-CoV2 (Li et al., 2020; Wang et al., 2020). Currently, patients diagnosed with COVID-19 are given a combination of nucleotide prodrug remdesivir and repurposed drug chloroquine, earlier used to treat malaria (Savarino et al., 2003; Li et al., 2020). While chloroquine inhibits the $\mathrm{pH}$-dependent viral replication steps and acts as the immunomodulator by suppressing the activation and release of IL- 6 and TNF- $\alpha$ (Savarino et al., 2003; Golden et al., 2015), remdesivir is believed to interfere with the NSP12 polymerase (Agostini et al., 2018), intravenous administration of which resulted in the decline of viral load detected on a nasopharyngeal swab of a first case of COVID-19 in Washington, United States (Ko et al., 2020). Administration of 

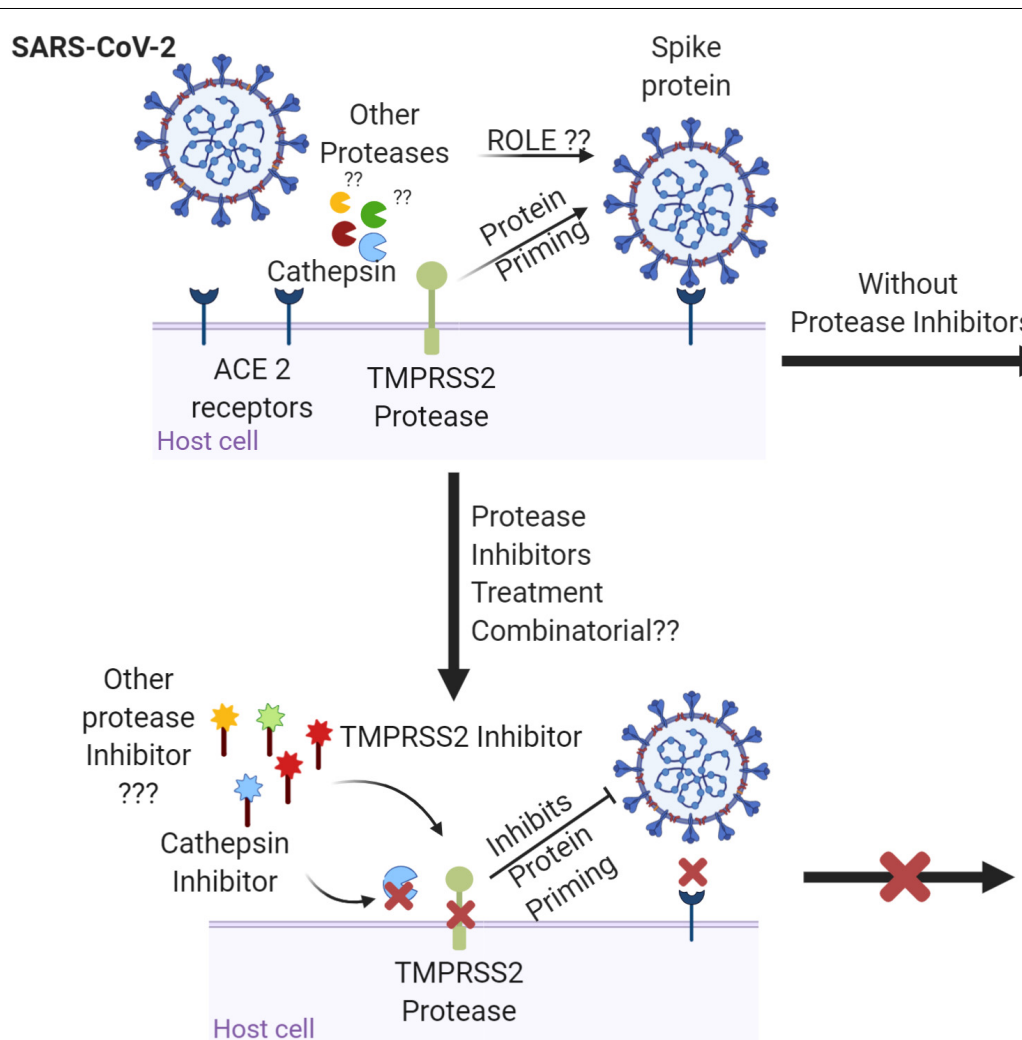

Fusion of SARS-CoV-2 with

Without Protease Inhibitors
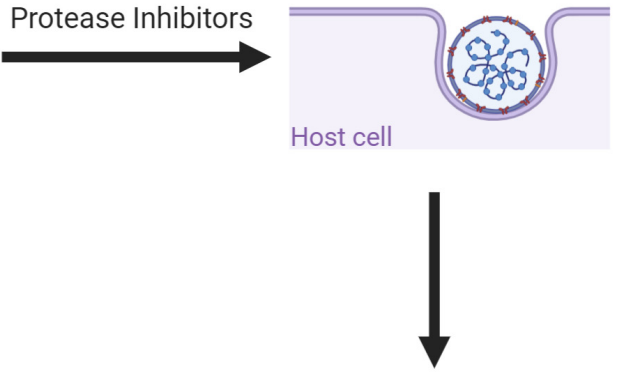

$\uparrow$ Viral Cell Replication $\uparrow$ Inflammation $\uparrow$ Neutrophils $\uparrow$ CD4+ T-Cells Cytokine-Storm

FIGURE 1 | Representation of the binding of the spike protein on the surface of SARS-CoV-2 to the ACE2 receptors on the surface of the host cell. TMPRSS2 and cathepsin are involved in priming of the $S$ glycoprotein and promoting viral invasion, leading to imbalance in the immune response and disease severity. Are other proteases involved in the proteolytic cascade of viral invasion? Targeting the proteases with specific protease inhibitors either alone or in combination may have better therapeutic potential for SARS-COV-2 infections. Figure prepared on biorender.com, professional science figure creating platform.

convalescent plasma derived from a COVID19-recovered patient with high SARS-CoV-2 specific antibody and neutralizing titre to five critically ill patients led to the improvement of their clinical symptoms (Shen et al., 2020). As these results were not obtained in controlled conditions, further clinical trials and studies would be required to understand the antiviral viral effect of the drugs and therapy on the immune system in bringing down the viral load.

Gathering the existing knowledge regarding vaccine development in SARS and MERS infection, many research groups have initiated the development of vaccines against SARS-CoV-2 considering different vaccine platforms like nucleotide-based, subunit-based, inactivated virus, and live attenuated virus-based platforms (Prompetchara et al., 2020). Full-length S1 proteins containing RBD can be considered as a potential antigen target, as neutralizing bodies against S1 can hinder host cell attachment and infection (Du et al., 2009; Al-Amri et al., 2017). As, the vaccine development would be the final prophylactic approach against SARS$\mathrm{CoV}-2$, it is time consuming and requires substantial research on issues such as immunization route, scalability, immune protection, production, and target product profile (Prompetchara et al., 2020). In contrast, targeting key proteases (viral and/or host) involved in viral entry and proliferation can be considered as an effective approach to alleviate the epidemic. Recent research has confirmed a significant decrease of SARS-CoV-2 viral load in Korean patients diagnosed with COVID-19 (Lim et al., 2020) when treated with protease inhibitor lopinavir and ritonavir, earlier used to treat human immunodeficiency virus (HIV) (Cvetkovic and Goa, 2003). Further studies targeting other host proteases may include cathepsins, granzymes, serine proteases, and proteases derived from various immune cells, responsible for viral entry, propagation, and altered innate and adaptive immune response.

Collecting our current understanding on role of proteases, it is suggested that a two-armed clinical approach, focusing on the combinatorial inhibition of host/virus protease dependent viral entry and controlled immune response, could be applied for a more robust response against SARS-CoV-2. Researchers have already commenced investigating the NSP5 main protease $\left(\mathrm{M}^{p r o}, 3 \mathrm{C}\right)$ as a potential drug target because of its involvement in processing the proteins coded from viral RNA (Zhang et al., 2020). An important aspect to consider while manipulating the host protease activity would be the specificity of the drugs against the targeted protease. As these proteases might be involved in 


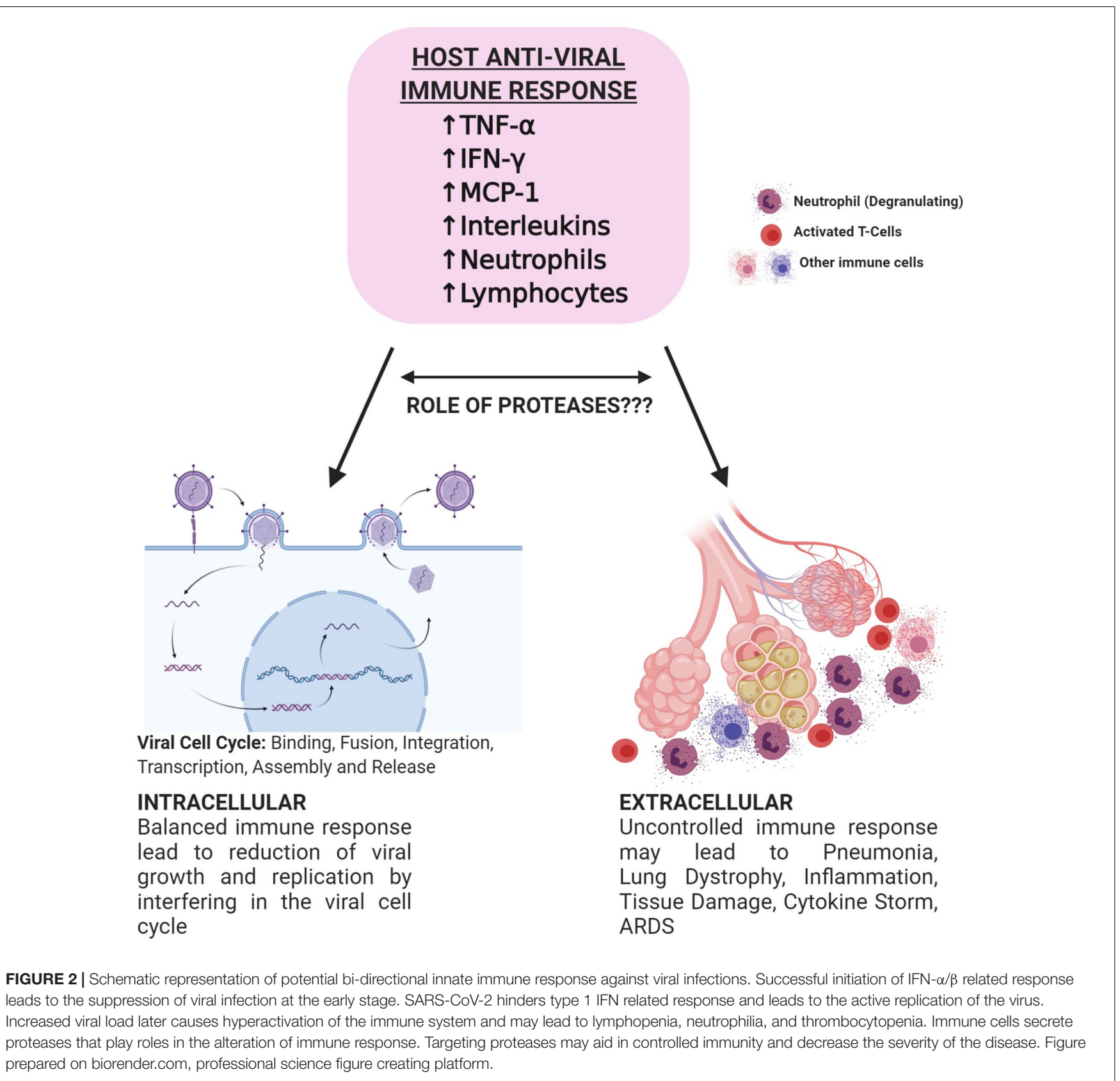

other biological processes, non-specific inhibition might lead to impairment of the regular physiological functioning of the host.

\section{CONCLUSION}

The COVID-19 epidemic not only affected the health of patients suffering from the disease but also left the entire world in deep financial and psychological distress. Although no promising treatment or vaccine has yet been discovered, research groups have been able to understand the genome of the novel virus, aiding them to develop vaccines and drugs against the therapeutic targets. Utilizing the host translational machinery for viral growth and propagation, SARS-CoV-2 entry to host cell is driven by the S-protein by engaging ACE2 and TMPRSS2 cell receptors. The activation of these receptors depends on the activity of various host proteases. In addition, to assist the functioning of cell receptors, multiple proteases are involved in host immune response against viral invasion and immunopathology related to imbalanced immune activation. This review, in relation to the prior knowledge on SARS-CoV and MERS-CoV, suggests a multidisciplinary approach, targeting host proteases against the cellular entry of coronaviruses through $S$-glycoprotein and host immune response against SARS-CoV2. It is of interest to know that mutations observed in the spike protein of SARS-CoV-2 might lead to high affinity binding to the ACE2 
host receptor in the presence of cathepsin and serine protease TMPRSS2 when compared to SARS-CoV host cell receptor attachment. Based on the understanding of the host immune response against viral infection, it could be brought into light that the imbalanced immune cells' activity can lead to the self-destruction of the host, resulting in a high severity of COVID-19. The significant role played by serine protease TMPRSS2 and other proteases, like cathepsins, plasmin, and KLKs, in priming the S-protein and promoting viral-host cell fusion has opened new avenues to study the role of various proteases in different cellular factors involved in SARS-CoV-2 invasion. Furthermore, unraveling the proteolytic web involved in the host immune response might provide insights into disease severity and reveal therapeutic targets. It is believed that this knowledge may aid in overcoming the hindrance encountered in targeting the viral sub-units of constantly evolving strains of SARS-CoV-2 and aid to develop quicker and more effective responses to extreme outcomes of the ongoing pandemic.

\section{REFERENCES}

Agostini, M. L., Andres, E. L., Sims, A. C., Graham, R. L., Sheahan, T. P., Lu, X., et al. (2018). Coronavirus Susceptibility to the Antiviral Remdesivir (GS-5734) Is Mediated by the Viral Polymerase and the Proofreading Exoribonuclease. mBio 9, e221-e218. doi: 10.1128/mBio.00221-18

Al-Amri, S. S., Abbas, A. T., Siddiq, L. A., Alghamdi, A., Sanki, M. A., Al-Muhanna, M. K., et al. (2017). Immunogenicity of Candidate MERS-CoV DNA Vaccines Based on the Spike Protein. Sci. Rep. 7:44875. doi: 10.1038/srep44875

Alexopoulou, L., Holt, A. C., Medzhitov, R., and Flavell, R. A. (2001). Recognition of double-stranded RNA and activation of NF-kappaB by Toll-like receptor 3 . Nature 413, 732-738. doi: 10.1038/35099560

Angeletti, S., Benvenuto, D., Bianchi, M., Giovanetti, M., Pascarella, S., and Ciccozzi, M. (2020). COVID-2019: The role of the nsp2 and nsp3 in its pathogenesis. J. Med. Virol. 92, 584-588. doi: 10.1002/jmv.25719

Baas, T., Taubenberger, J. K., Chong, P. Y., Chui, P., and Katze, M. G. (2006). SARS$\mathrm{CoV}$ virus-host interactions and comparative etiologies of acute respiratory distress syndrome as determined by transcriptional and cytokine profiling of formalin-fixed paraffin-embedded tissues. J. Interf. Cytok. Res. 26, 309-317. doi: 10.1089/jir.2006.26.309

Bertram, S., Glowacka, I., Müller, M. A., Lavender, H., Gnirss, K., Nehlmeier, I., et al. (2011). Cleavage and activation of the severe acute respiratory syndrome coronavirus spike protein by human airway trypsin-like protease. J. Virol. 85, 13363-13372. doi: 10.1128/JVI.05300-11

Cameron, M. J., Ran, L., Xu, L., Danesh, A., Bermejo-Martin, J. F., Cameron, C. M., et al. (2007). Interferon-mediated immunopathological events are associated with atypical innate and adaptive immune responses in patients with severe acute respiratory syndrome. J. Virol. 81, 8692-8706. doi: 10.1128/jvi.005 27-07

Chen, C., Zhang, X. R., Ju, Z. Y., and He, W. F. (2020). [Advances in the research of cytokine storm mechanism induced by Corona Virus Disease 2019 and the corresponding immunotherapies]. Zhonghua Shao Shang Za Zhi 36:E005. doi: 10.3760/cma.j.cn501120-20200224-00088

Coutard, B., Valle, C., de Lamballerie, X., Canard, B., Seidah, N. G., and Decroly, E. (2020). The spike glycoprotein of the new coronavirus 2019-nCoV contains a furin-like cleavage site absent in $\mathrm{CoV}$ of the same clade. Antiviral Res. 176:104742. doi: 10.1016/j.antiviral.2020.104742

Cui, J., Li, F., and Shi, Z. L. (2019). Origin and evolution of pathogenic coronaviruses. Nat. Rev. Microbiol. 17, 181-192. doi: 10.1038/s41579-0180118-9

Cvetkovic, R. S., and Goa, K. L. (2003). Lopinavir/ritonavir: a review of its use in the management of HIV infection. Drugs 63, 769-802. doi: 10.2165/00003495200363080-00004

\section{AUTHOR CONTRIBUTIONS}

SrS presented the concept of review and edited it. SaS wrote the manuscript. JB contributed to the editing of the manuscript. All the authors contributed to the article and approved the submitted version.

\section{FUNDING}

This work was supported by the NHMRC Career Development Fellowship and Advance QLD MCR Research Fellowship to JB. SrS was supported by Advance QLD ECR Research Fellowship.

\section{ACKNOWLEDGMENTS}

Thanks to Ms. Oishee Chatterjee for her contribution and help for preparing images.

de Wit, E., van Doremalen, N., Falzarano, D., and Munster, V. J. (2016). SARS and MERS: recent insights into emerging coronaviruses. Nat. Rev. Microbiol. 14, 523-534. doi: 10.1038/nrmicro.2016.81

Du, L., He, Y., Zhou, Y., Liu, S., Zheng, B. J., and Jiang, S. (2009). The spike protein of SARS-CoV-a target for vaccine and therapeutic development. Nat. Rev. Microbiol. 7, 226-236. doi: 10.1038/nrmicro2090

Glowacka, I., Bertram, S., Müller, M. A., Allen, P., Soilleux, E., Pfefferle, S., et al. (2011). Evidence that TMPRSS2 Activates the Severe Acute Respiratory Syndrome Coronavirus Spike Protein for Membrane Fusion and Reduces Viral Control by the Humoral Immune Response. J. Virol. 85:4122. doi: 10.1128/JVI. 02232-10

Golden, E. B., Cho, H. Y., Hofman, F. M., Louie, S. G., Schonthal, A. H., and Chen, T. C. (2015). Quinoline-based antimalarial drugs: a novel class of autophagy inhibitors. Neurosurg. Focus 38:E12. doi: 10.3171/2014.12.Focus14748

Guo, Y.-R., Cao, Q.-D., Hong, Z.-S., Tan, Y.-Y., Chen, S.-D., Jin, H.-J., et al. (2020). The origin, transmission and clinical therapies on coronavirus disease 2019 (COVID-19) outbreak-an update on the status. Milit. Med. Res. 7:11. doi: 10.1186/s40779-020-00240-0

Hagn, M., Schwesinger, E., Ebel, V., Sontheimer, K., Maier, J., Beyer, T., et al. (2009). Human B Cells Secrete Granzyme B When Recognizing Viral Antigens in the Context of the Acute Phase Cytokine IL-21. J. Immunol. 183:1838. doi: 10.4049/jimmunol.0901066

Heutinck, K. M., ten Berge, I. J. M., Hack, C. E., Hamann, J., and Rowshani, A. T. (2010). Serine proteases of the human immune system in health and disease. Mol. Immunol. 47, 1943-1955. doi: 10.1016/j.molimm.2010.04.020

Hoffmann, M., Kleine-Weber, H., Schroeder, S., Krüger, N., Herrler, T., Erichsen, S., et al. (2020). SARS-CoV-2 Cell Entry Depends on ACE2 and TMPRSS2 and Is Blocked by a Clinically Proven Protease Inhibitor. Cell 181, 271-280.e. doi: 10.1016/j.cell.2020.02.052

Hussain, S., Pan, J., Chen, Y., Yang, Y., Xu, J., and Guo, D. (2005). Identification of Novel Subgenomic RNAs and Noncanonical Transcription Initiation Signals of Severe Acute Respiratory Syndrome Coronavirus. J. Virol. 79:5288. doi: 10. 1128/JVI.79.9.5288-5295.2005

Jahrsdörfer, B., Vollmer, A., Blackwell, S. E., Maier, J., Sontheimer, K., Beyer, T., et al. (2010). Granzyme B produced by human plasmacytoid dendritic cells suppresses T-cell expansion. Blood 115, 1156-1165. doi: 10.1182/blood-200907-235382

Ji, H.-L., Zhao, R., Matalon, S., and Matthay, M. A. (2020). Elevated Plasmin(ogen) as a Common Risk Factor for COVID-19 Susceptibility. Physiol. Rev. 100, 1065-1075. doi: 10.1152/physrev.00013.2020

Kawai, T., and Akira, S. (2010). The role of pattern-recognition receptors in innate immunity: update on Toll-like receptors. Nat. Immunol. 11, 373-384. doi: $10.1038 /$ ni.1863 
Kido, H., Okumura, Y., Takahashi, E., Pan, H.-Y., Wang, S., Yao, D., et al. (2012). Role of host cellular proteases in the pathogenesis of influenza and influenzainduced multiple organ failure. Biochim. Biophys. Acta Prot. Proteom. 1824, 186-194. doi: 10.1016/j.bbapap.2011.07.001

Ko, W. C., Rolain, J. M., Lee, N. Y., Chen, P. L., Huang, C. T., Lee, P. I., et al. (2020). Arguments in favour of remdesivir for treating SARS-CoV-2 infections. Int. J. Antimicrob. Agents 55:105933. doi: 10.1016/j.ijantimicag.2020.10 5933

Letko, M., Marzi, A., and Munster, V. (2020). Functional assessment of cell entry and receptor usage for SARS-CoV-2 and other lineage B betacoronaviruses. Nat. Microbiol. 5, 562-569. doi: 10.1038/s41564-020-0688-y

Leu, C.-H., Yang, M.-L., Chung, N.-H., Huang, Y.-J., Su, Y.-C., Chen, Y.-C., et al. (2015). Kallistatin ameliorates influenza virus pathogenesis by inhibition of kallikrein-related peptidase 1-mediated cleavage of viral hemagglutinin. Antimicrob. Agents Chemother. 59, 5619-5630. doi: 10.1128/AAC.00 065-15

Li, H., Wang, Y. M., Xu, J. Y., and Cao, B. (2020). [Potential antiviral therapeutics for 2019 Novel Coronavirus]. Zhonghua Jie He He Hu Xi Za Zhi 43:E002. doi: 10.3760/cma.j.issn.1001-0939.2020.0002

Lim, J., Jeon, S., Shin, H. Y., Kim, M. J., Seong, Y. M., Lee, W. J., et al. (2020). Case of the Index Patient Who Caused Tertiary Transmission of COVID-19 Infection in Korea: the Application of Lopinavir/Ritonavir for the Treatment of COVID19 Infected Pneumonia Monitored by Quantitative RT-PCR. J. Korean Med. Sci. 35:e79. doi: 10.3346/jkms.2020.35.e79

Magnen, M., Gueugnon, F., Guillon, A., Baranek, T., Thibault, V. C., Petit-Courty, A., et al. (2017). Kallikrein-Related Peptidase 5 Contributes to H3N2 Influenza Virus Infection in Human Lungs. J. Virol. 91, e421-e417. doi: 10.1128/JVI. 00421- 17

Mambole, A., Baruch, D., Nusbaum, P., Bigot, S., Suzuki, M., Lesavre, P., et al. (2008). The cleavage of neutrophil leukosialin (CD43) by cathepsin G releases its extracellular domain and triggers its intramembrane proteolysis by presenilin/gamma-secretase. J. Biol. Chem. 283, 23627-23635. doi: 10.1074/jbc. M710286200

Matsuyama, S., Nagata, N., Shirato, K., Kawase, M., Takeda, M., and Taguchi, F. (2010). Efficient activation of the severe acute respiratory syndrome coronavirus spike protein by the transmembrane protease TMPRSS2. J. Virol. 84, 1265812664. doi: 10.1128/jvi.01542-10

Méthot, N., Rubin, J., Guay, D., Beaulieu, C., Ethier, D., Reddy, T. J., et al. (2007). Inhibition of the activation of multiple serine proteases with a cathepsin $\mathrm{C}$ inhibitor requires sustained exposure to prevent pro-enzyme processing. J. Biol. Chem. 282, 20836-20846. doi: 10.1074/jbc.M702615200

Milewska, A., Falkowski, K., Kalinska, M., Bielecka, E., Naskalska, A., Mak, P., et al. (2020). Kallikrein 13: a new player in coronaviral infections. bioRxiv 2020. doi: 10.1101/2020.03.01.971499

Millet, J. K., and Whittaker, G. R. (2015). Host cell proteases: Critical determinants of coronavirus tropism and pathogenesis. Virus Res. 202, 120-134. doi: 10.1016/ j.virusres.2014.11.021

Morice, W. G., Jevremovic, D., and Hanson, C. A. (2007). The expression of the novel cytotoxic protein granzyme $\mathrm{M}$ by large granular lymphocytic leukaemias of both T-cell and NK-cell lineage: an unexpected finding with implications regarding the pathobiology of these disorders. Br. J. Haematol. 137, 237-239. doi: $10.1111 / \mathrm{j} .1365-2141.2007 .06564 . \mathrm{x}$

Nakamura, H., Yoshimura, K., McElvaney, N. G., and Crystal, R. G. (1992). Neutrophil elastase in respiratory epithelial lining fluid of individuals with cystic fibrosis induces interleukin-8 gene expression in a human bronchial epithelial cell line. J. Clin. Invest. 89, 1478-1484. doi: 10.1172/JCI115738

Pejler, G., Åbrink, M., Ringvall, M., and Wernersson, S. (2007). Mast Cell Proteases. Adv. Immunol. 95, 167-255.

Perrier, A., Bonnin, A., Desmarets, L., Danneels, A., Goffard, A., Rouille, Y., et al. (2019). The C-terminal domain of the MERS coronavirus M protein contains a trans-Golgi network localization signal. J. Biol. Chem. 294, 14406-14421. doi: 10.1074/jbc.RA119.008964

Prompetchara, E., Ketloy, C., and Palaga, T. (2020). Immune responses in COVID19 and potential vaccines: Lessons learned from SARS and MERS epidemic. Asian Pac. J. Allergy Immunol. 38, 1-9. doi: 10.12932/ap-200220-0772

Reid, J. C., Matsika, A., Davies, C. M., He, Y., Broomfield, A., Bennett, N. C., et al. (2017). Pericellular regulation of prostate cancer expressed kallikrein-related peptidases and matrix metalloproteinases by cell surface serine proteases. Am. J. Cancer Res. 7, 2257-2274.

Roghanian, A., and Sallenave, J.-M. (2008). Neutrophil Elastase (NE) and NE Inhibitors Canonical and Noncanonical Functions in Lung Chronic Inflammatory Diseases (Cystic Fibrosis and Chronic Obstructive Pulmonary Disease). J. Aerosol. Med. Pulm. Drug Deliv. 21, 125-144. doi: 10.1089/jamp. 2007.0653

Savarino, A., Boelaert, J. R., Cassone, A., Majori, G., and Cauda, R. (2003). Effects of chloroquine on viral infections: an old drug against today's diseases? Lancet Infect. Dis. 3, 722-727. doi: 10.1016/s1473-3099(03)0 0806-5

Sawicki, S. G., and Sawicki, D. L. (2005). Coronavirus transcription: a perspective. Curr. Top. Microbiol. Immunol 287, 31-55. doi: 10.1007/3-540-26765-4_2

Seidah, N. G., and Prat, A. (2012). The biology and therapeutic targeting of the proprotein convertases. Nat. Rev. Drug Discov. 11, 367-383. doi: 10.1038/ nrd3699

Shahabi, F., Mosaddeghi, P., Negahdaripour, M., Dehghani, Z., Farahmandnejad, M., Moghadami, M., et al. (2020). Therapeutic Approaches for COVID-19 Based on the Dynamics of Interferon-mediated Immune Responses. Preprints 2020:2020030206.

Shen, C., Wang, Z., Zhao, F., Yang, Y., Li, J., Yuan, J., et al. (2020). Treatment of 5 Critically Ill Patients With COVID-19 With Convalescent Plasma. JAMA 323(16), 1582-1589. doi: 10.1001/jama.2020.4783

Simmons, G., Gosalia, D. N., Rennekamp, A. J., Reeves, J. D., Diamond, S. L., and Bates, P. (2005). Inhibitors of cathepsin L prevent severe acute respiratory syndrome coronavirus entry. Proc. Natl. Acad. Sci. U.S.A. 102, 11876-11881. doi: 10.1073/pnas.0505577102

Song, W., Gui, M., Wang, X., and Xiang, Y. (2018). Cryo-EM structure of the SARS coronavirus spike glycoprotein in complex with its host cell receptor ACE2. PLoS Pathog. 14:e1007236. doi: 10.1371/journal.ppat.10 07236

Straus, M. R., Kinder, J. T., Segall, M., Dutch, R. E., and Whittaker, G. R. (2020). SPINT2 inhibits proteases involved in activation of both influenza viruses and metapneumoviruses. Virology 543, 43-53. doi: 10.1016/j.virol.2020. 01.004

Sun, X., Tse, L. V., Ferguson, A. D., and Whittaker, G. R. (2010). Modifications to the Hemagglutinin Cleavage Site Control the Virulence of a Neurotropic H1N1 Influenza Virus. J. Virol. 84:8683. doi: 10.1128/JVI.00797-10

Tang, F., Liu, W., Zhang, F., Xin, Z.-T., Wei, M.-T., Zhang, P.-H., et al. (2008). IL-12 RB1 Genetic Variants Contribute to Human Susceptibility to Severe Acute Respiratory Syndrome Infection among Chinese. PLoS One 3:e2183. doi: 10.1371/journal.pone.0002183

Tang, N. L.-S., Chan, P. K.-S., Wong, C.-K., To, K.-F., Wu, A. K.-L., Sung, Y.M., et al. (2005). Early enhanced expression of interferon-inducible protein-10 (CXCL-10) and other chemokines predicts adverse outcome in severe acute respiratory syndrome. Clin. Chem. 51, 2333-2340. doi: 10.1373/clinchem.2005. 054460

Tortorici, M. A., and Veesler, D. (2019). Structural insights into coronavirus entry. Adv. Virus Res. 105, 93-116. doi: 10.1016/bs.aivir.2019.08.002

van der Geld, Y. M., Limburg, P. C., and Kallenberg, C. G. M. (2001). Proteinase 3, Wegener's autoantigen: from gene to antigen. J. Leukoc. Biol. 69, 177-190. doi: $10.1189 /$ jlb.69.2.177

Wang, D., Hu, B., Hu, C., Zhu, F., Liu, X., Zhang, J., et al. (2020). Clinical Characteristics of 138 Hospitalized Patients With 2019 Novel CoronavirusInfected Pneumonia in Wuhan. China. JAMA 323, 1061-1069. doi: 10.1001/ jama.2020.1585

Wang, H., Yi, T., Zheng, Y., and He, S. (2007). Induction of monocyte chemoattractant protein-1 release from A549 cells by agonists of proteaseactivated receptor-1 and -2. Eur. J. Cell Biol. 86, 233-242. doi: 10.1016/j.ejcb. 2006.12.003

Wu, A., Peng, Y., Huang, B., Ding, X., Wang, X., Niu, P., et al. (2020). Genome Composition and Divergence of the Novel Coronavirus (2019-nCoV) Originating in China. Cell Host Microbe 27, 325-328. doi: 10.1016/j.chom.2020. 02.001

Wu, F., Zhao, S., Yu, B., Chen, Y.-M., Wang, W., Song, Z.-G., et al. (2020). A new coronavirus associated with human respiratory disease in China. Nature 579, 265-269. doi: 10.1038/s41586-020-2008-3 
Wu, J., and Chen, Z. J. (2014). Innate immune sensing and signaling of cytosolic nucleic acids. Annu. Rev. Immunol. 32, 461-488. doi: 10.1146/annurevimmunol-032713-120156

Zhang, L., Lin, D., Sun, X., Curth, U., Drosten, C., Sauerhering, L., et al. (2020). Crystal structure of SARS-CoV-2 main protease provides a basis for design of improved alpha-ketoamide inhibitors. Science 368, 409-412. doi: 10.1126/ science.abb3405

Zhang, N., Jiang, S., and Du, L. (2014). Current advancements and potential strategies in the development of MERS-CoV vaccines. Expert Rev. Vaccines 13, 761-774. doi: 10.1586/14760584.2014.912134

Zhou, P., Yang, X.-L., Wang, X.-G., Hu, B., Zhang, L., Zhang, W., et al. (2020). A pneumonia outbreak associated with a new coronavirus of probable bat origin. Nature 579, 270-273. doi: 10.1038/s41586-020-2012-7

Zhu, N., Zhang, D., Wang, W., Li, X., Yang, B., Song, J., et al. (2020). A Novel Coronavirus from Patients with Pneumonia in China, 2019. N. Engl. J. Med. 382, 727-733. doi: 10.1056/NEJMoa2001017
Zhu, P., Martinvalet, D., Chowdhury, D., Zhang, D., Schlesinger, A., and Lieberman, J. (2009). The cytotoxic T lymphocyte protease granzyme A cleaves and inactivates poly(adenosine 5'-diphosphate-ribose) polymerase-1. Blood 114, 1205-1216. doi: 10.1182/blood-2008-12-19 5768

Conflict of Interest: The authors declare that the research was conducted in the absence of any commercial or financial relationships that could be construed as a potential conflict of interest.

Copyright (c) 2020 Seth, Batra and Srinivasan. This is an open-access article distributed under the terms of the Creative Commons Attribution License (CC BY). The use, distribution or reproduction in other forums is permitted, provided the original author(s) and the copyright owner(s) are credited and that the original publication in this journal is cited, in accordance with accepted academic practice. No use, distribution or reproduction is permitted which does not comply with these terms. 